\title{
Marx contra o otimismo tecnológico: economia "imaterial" desmistificada e desdobramentos para as questões ambientais
}

Marx against technological optimism: demystified "immaterial" economy and outcomes concerning environmental issues

Eduardo Sá Barreto

Universidade Federal de Juiz de Fora

\begin{abstract}
In previous papers, we have conducted a broad review of the economic literature concerning environmental debates (especially the debate on climate change). In general, the several considerations - ranging from the ones built upon neoclassical theory to the ones based on heterodox thinking tend to converge, with very few exceptions, to the notion of dematerialization; or, to put it clearly, to the hope that technological development will allow for the realization of a supposedly immaterial production. This paper starts from these previous assessments and has the objective of demystifying (that is, deconstructing critically) the notion of dematerialization as a real possibility in the present socioeconomic formation. Along with the very nature of this critique, we simultaneously intend to offer a theoretical argument of our own, rooted in Marx's thinking and capable of explaining why the faith in the dematerialization process tends to be systematically frustrated as long as the production and distribution of social wealth is structured around capital.
\end{abstract}

\section{Keywords}

technology; dematerialization; Marx.

JEL Codes B51; O30; Q00.

\section{Resumo}

Em trabalhos anteriores, realizamos uma abrangente revisão da literatura econômica relacionada ao debate ambiental (especialmente aquele em torno das mudanças climáticas). De modo geral, as diversas formulações - desde aquelas apoiadas na estrutura teórica neoclássica até as mais heterodoxas - tendem a confluir, com poucas exceções, para a noção de desmaterialização; ou, melhor dizendo, para a esperança de que o avanço tecnológico permita a realização de uma produção supostamente imaterial. O presente estudo parte dessa leitura e tem como objetivo a desmistificação (i.e. sua desconstrução crítica) da desmaterialização como possibilidade real na atual formação socioeconômica. Pela própria natureza desse expediente crítico, simultaneamente propomos um argumento teórico próprio, alicerçado em Marx, capaz de explicar por que a esperança no processo de desmaterialização tende a ser frustrada sistematicamente enquanto a lógica da produção e da distribuição da riqueza social estiver estruturada em torno do capital.

\section{Palavras-chave \\ tecnologia; desmaterialização; Marx.}

Códigos JEL B51; O30; Q00. 


\section{Introdução}

O debate relacionado às questões ambientais com base em uma perspectiva econômica encontra na Economia Ambiental e na Economia Ecológica suas duas principais correntes de pensamento. A despeito de algumas diferenças marcantes entre os fundamentos teóricos de cada uma dessas correntes, o teor das intervenções não é tão divergente quanto se poderia esperar a princípio.

Por um lado, a Economia Ambiental parte do campo teórico neoclássico e conflui (com inúmeras mediações, evidentemente) para a conclusão geral de que o progresso tecnológico traz consigo uma possibilidade poupadora de recursos que - se presentes os mecanismos de ajuste de mercado previstos em teoria - é plenamente realizada. Por outro lado, a Economia Ecológica parte de uma perspectiva alternativa (heterodoxa do ponto de vista da ciência econômica) e interdisciplinar, incorporando contribuições da física, biologia, geoquímica, etc. Ainda assim, o sentido geral das formulações desta corrente converge significativamente para aquele observado na Economia Ambiental. Nesse caso, como no anterior, a tecnologia também teria a propriedade de expandir as possibilidades de economia de recursos. Ao contrário do que se observa na Economia Ambiental, entretanto, o entendimento mais comum na Economia Ecológica é que tais possibilidades costumam ser sistematicamente frustradas por padrões de consumo não sustentáveis. Mesmo assim, argumenta-se, por meio de uma reorientação desses padrões - uma espécie de tomada de consciência universal daria à luz padrões de consumo sustentáveis - a economia de recursos seria, enfim, igualmente realizável. ${ }^{1}$

A noção de economia (ou poupança) de recursos é o princípio que sustenta o conceito mais abrangente de desmaterialização da produção. Esse conceito é central tanto nas formulações da Economia Ambiental quanto nas da Economia Ecológica. Em torno dele, são erigidas as expectativas de que a assim chamada produção imaterial seja uma meta realizável.

Os contornos fundamentais das alegações em torno da desmaterialização podem ser sumarizados em dois pontos. Em primeiro lugar, o crescimento econômico é tomado (em geral a priori) como um impe- 
rativo- i.e., como um valor, que apenas muito raramente ${ }^{2}$ é questionado. A tal crescimento, porém, não corresponderia necessariamente uma expansão (material) da produção ou do consumo produtivo, o que nos leva ao segundo ponto. A chave dessa não correspondência seria o desenvolvimento tecnológico. A tecnologia, como poupadora de recursos, facultaria a expansão econômica sobre uma base material não expansiva (ou, em proposições menos radicais, ao menos não proporcionalmente expansiva).

É necessário sublinhar, mais uma vez, o peso que uma concepção de tal natureza adquire em reflexões voltadas aos problemas ambientais contemporâneos (alguns deles em escala efetivamente global). A promessa que ela carrega, ainda que de forma velada, é a de uma extraordinária abundância imaterial (e, portanto, livre de empecilhos ambientais).

$\bigcirc$ objetivo central deste trabalho é demonstrar ${ }^{3}$ os limites estruturais objetivos à realização dessas alegações no interior da dinâmica própria do modo de produção regido pelo capital. Tal tarefa não é empreendida nas formulações valendo-se da Economia Ecológica e, principalmente, da Economia Ambiental. O "silêncio" a respeito dos limites da atual formação socioeconômica não chega, contudo, a surpreender. As intervenções que analisamos subentendem uma ontologia, uma visão de mundo, na qual a sociedade do capital figura como estágio último do desenvolvimento humano e, portanto, fora da esfera de questionamentos. Nesses casos, o esforço científico contenta-se, em geral inconscientemente, com um trabalho de Sísifo de buscar, ininterruptamente, formas de poupar em meio a uma formidável (e estrutural) prodigalidade. ${ }^{4}$ Como diria Mészáros (2002, p. 525), ${ }^{5}$ em vez da necessária investigação dos mecanismos causais, "recebemos a oferta de uma 'transição' dos conjuntos dados de relações sociais para a sua reprodução [...] numa forma parcialmente alterada mas estruturalmente idêntica".

2 Cf. Kallis (2011) e van den Bergh (2011).

3 A demonstração situa-se num plano de abstração razoavelmente elevado. Determinações políticas, por exemplo, não são ainda contempladas no presente trabalho.

4 Por outro lado, tampouco buscamos oferecer uma crítica positiva da ausência (nos debates teóricos e nas iniciativas políticas) de considerações quanto à possibilidade de que o capital encontre um limite absoluto à sua perpetuação. O que é realmente alarmante, em nosso juízo, é que o capital, ao desenvolver-se rumo ao seu limite (e ruína) material, destrua consigo as condições materiais que poderiam vir a sustentar novas formas de organização do metabolismo sociorreprodutivo.

5 A afirmação de Mészáros refere-se a outro contexto, mas é pertinente também para este. 
Mais precisamente, pretende-se aqui desenvolver um argumento (partindo da perspectiva teórica marxiana) capaz de acessar os limites de realização, na sociedade capitalista, de estratégias de desenvolvimento sustentável erigidas em torno do conceito de desmaterialização. A segunda seção busca demonstrar o caráter autoexpansivo imanente do capital e, com isso, da produção organizada em torno do (e regida pelo) capital. A terceira seção, com duas subseções, busca combinar esse argumento (no qual apenas se entrevê os desdobramentos materiais) à sua dimensão material. Assim, espera-se, será possível mostrar como a dinâmica tecnológica é funcional e necessária ao movimento expansivo do capital e, ao mesmo tempo, traduz tal movimento em uma dimensão material também expansiva.

\section{Expansão da produção como necessidade imanente ${ }^{6}$}

Como afirmado na seção anterior, um dos traços mais evidentes de todo o debate em torno das possibilidades de desmaterialização da produção é o caráter axiomático que o crescimento econômico assume em praticamente todas as intervenções. Nas raras ocasiões em que se encontra alguma discussão ou investigação específica sobre esse tema, o foco das reflexões é usualmente direcionado ao aspecto qualitativo da expansão econômica. Em outros termos, quando se discute crescimento econômico, a questão geralmente formulada é: "que tipo de crescimento econômico podemos, queremos ou deveríamos ter?". A dimensão expansionista do processo econômico, entretanto, está sempre dada desde o início.

Não é preciso, porém, debruçar-se sobre a literatura especializada para constatar a circulação onipresente desse tipo de concepção. $\bigcirc$ não crescimento econômico é prontamente proclamado como indesejável não somente na teoria econômica, mas também na imprensa especializada, nos telejornais direcionados ao público em geral, nas conversas cotidianas, etc. Decrescimento econômico, por sua vez, equivale à crise em quase todas as mentes. O problema, entretanto, é que tal naturalização generalizada do ímpeto expansivo da produção não é mera concepção falsa ou equivocada. A base dessa mistificação - que transforma, nas concepções em geral, no Livro I de O Capital. (Marx, 2012[1867]) 
o imperativo do crescimento econômico em condição "natural" da sociedade - deve ser analisada.

Com esse intuito, a primeira seção busca demonstrar a necessidade imanente da expansão da produção na sociedade regida pelo capital. Com isso, também pretendemos dar um primeiro passo no desenvolvimento de uma reinterpretação da interação dinâmica entre produção e consumo material (na atividade humana entendida em sentido global).

De modo a oferecer uma primeira aproximação a esse novo entendimento é preciso, se partimos de uma perspectiva marxiana, retomar a análise fundada na categoria do valor e, mais especificamente, do valor como capital.

O valor-capital distingue-se do valor (tomado simplesmente como categoria da troca) primeiramente pela sua forma de circulação. $O$ valor transformado em capital não segue o circuito descrito pela circulação simples de mercadorias (M-D-M), mas passa a circular segundo o circuito D-M-D'. Esta, no entanto, não é mera mudança de forma; é uma forma distinta de circulação que carrega em si mudanças importantes de conteúdo.

Na primeira, o objetivo final do intercâmbio é sempre um valor de uso, destinado a atender a uma necessidade específica daquele que inicia o circuito realizando a venda de sua mercadoria. A despeito do impulso à expansão da produção já contido nessa forma de circulação - que, mesmo se abstraindo de categorias decisivas como o próprio capital, é regida pelo valor -, o fim do processo é sempre a retirada de uma mercadoria da circulação e sua realização como valor de uso. $O$ dinheiro muda continuamente de mãos, ocupando em cada ato de troca o lugar da mercadoria expelida. A operação renova-se, portanto, de acordo com a renovação da necessidade que a motivou; a repetição é determinada por uma "finalidade situada fora da operação" - o consumo do valor de uso.

$\mathrm{Na}$ segunda, muda o ponto de partida e a meta final do movimento. $\mathrm{O}$ valor de troca passa a ser o objetivo que impulsiona e determina todo o processo. $O$ dinheiro, que dá início ao circuito, retorna ao seu detentor original acrescido de mais-valor. ${ }^{8} \mathrm{O}$ não retorno, quando ocorre, caracteriza a operação como malsucedida. Sendo assim, o início e o fim do processo diferem apenas quantitativamente. Como o objetivo que orienta toda a operação é exatamente tal expansão quantitativa, o movimento renova-se

7 Em outros termos, condição que seria inerente a qualquer formação socioeconômica.

8 Seguimos a tradução de Mehrwert (usualmente traduzida como mais-valia) sugerida por Mario Duayer na edição brasileira dos Grudrisse. (Marx, 2011, p. 23) 
constantemente. ${ }^{9} \mathrm{Se}$, por algum motivo, a contínua repetição deste ciclo encontra um fim definitivo - p. ex., sendo o dinheiro ao final do processo utilizado em consumo pessoal do capitalista, não produtivo -, retorna-se a $\mathrm{M}-\mathrm{D}-\mathrm{M}$, e o dinheiro deixa de funcionar como capital; i.e., deixa de ser capital quando não repete continuamente o ciclo D-M-D'.

O retorno do dinheiro acrescido de mais-valor é determinado "pela maneira como foi despendido". Enquanto o entesourador acumula dinheiro retirando-o constantemente da circulação, o capitalista acumula lançando-o - e de maneira determinada - na circulação. Em outras palavras, deve o dinheiro ser despendido como capital. E o primeiro passo na transformação do valor em capital é a conversão de uma dada quantidade de valor-dinheiro em meios de produção e força de trabalho; o segundo consiste em lançar as mercadorias produzidas à circulação.

Naturalmente, é a dissolução de formações sociais pré-capitalistas (em particular do feudalismo europeu) que leva tanto a extensas expropriações de riqueza sob a forma não capitalista quanto a sua reapropriação como capital. Também é a dissolução das condições materiais necessárias à reprodução das classes de produtores coagidos por laços de compulsão direta (servos e escravos), de um lado, e a limitação produtiva das economias fracionadas de trabalhadores livres (artesanato e pequena produção campesina), de outro, que explicam o surgimento da classe de trabalhadores assalariados. Trabalhadores esses que, livres da coerção direta, mas "livres" também da propriedade dos meios de produção, aparecem em massa no mercado vendendo força de trabalho como mercadoria.

Como amplamente conhecido, o valor da força de trabalho é correspondente ao valor dos meios necessários à manutenção e reprodução (e por isso se inclui o necessário aos dependentes) de seus possuidores. Também é bem conhecida a demonstração de Marx de que o trabalho objetivado na força de trabalho e aquele que ela pode realizar são dissociados entre si. Em outros termos, o valor da força de trabalho e o valor que, ao ser empregada, ela pode criar são de magnitudes distintas. Basta, portanto, para a criação de mais-valor, que o tempo de trabalho socialmente necessário à manutenção e reprodução da força de trabalho seja inferior a uma jornada inteira, i.e., ao

9 "Se se cogita de aumentar o valor, haverá para as 110 libras o mesmo afã de acrescer-lhes o valor que havia para as 100 libras, uma vez que ambas são expressões limitadas do valor de troca, possuindo a tendência de se aproximarem da riqueza em sentido absoluto através da expansão de suas magnitudes". (Marx, 2012[1867], p. 182) 
tempo de trabalho despendido. ${ }^{10}$ Durante parte da jornada, o trabalhador reproduz o valor pago em salários e no restante cria mais-valor.

A existência da força de trabalho como mercadoria disponível no mercado é, pelo exposto, mais um dos traços fundamentais que caracteriza a época capitalista. Nessa condição, é pressuposto para a existência do capital. O capital tem, portanto, origem na circulação - por depender de encontrar a força de trabalho disponível no mercado - mas também fora dela, por depender da produção de mais-valor o seu processo de expansão. Pode-se afirmar, então, que a busca pelo valor de troca (ilustrada no início da seção pelo circuito D-M-D') é, na verdade, expressão fenomênica da busca pelo valor e, mais especificamente, pelo mais-valor.

A necessidade que se satisfaz com valores de uso passa, em tal caso, a estar subordinada a uma necessidade de outra natureza. A necessidade, na formação socioeconômica regida pelo capital, é a produção e a realização de mais-valor, sua transformação em dinheiro por meio da venda das mercadorias nas quais esse se incorpora.

A relação sintetizada na taxa de mais-valor como a razão entre o mais-valor e o valor adiantado em capital variável expressa a proporção em que o valor novo criado supera o valor adiantado em força de trabalho. Essa mesma relação pode também ser tomada como a razão entre parcelas determinadas de tempo de trabalho; como a relação entre o tempo que supera o necessário à reprodução do valor da força de trabalho (tempo de trabalho excedente) e o tempo de trabalho em que se reproduz valor equivalente ao capital variável (tempo de trabalho necessário).

Nesse registro, a proporção em que o valor novo criado se divide entre valor da força de trabalho e mais-valor é determinada pela duração da jornada e pela intensidade ${ }^{11}$ e produtividade ${ }^{12}$ do trabalho. Quanto mais longa a jornada, e consideradas constantes a produtividade e a intensidade do trabalho, maior a massa de valor produzida. Como o valor da força de trabalho, nessas condições, permanece inalterado, cresce também a massa de mais-valor.

10 Admitindo-se, evidentemente, que tal jornada ocorra ao menos sob as condições médias vigentes de produção.

11 Os efeitos da variação da intensidade serão abordados a partir da segunda seção.

12 "Entendemos aqui por elevação da produtividade do trabalho em geral uma modificação no processo de trabalho por meio da qual se encurta o tempo de trabalho socialmente necessário para a produção de uma mercadoria, conseguindo-se produzir, com a mesma quantidade de trabalho, quantidade maior de valor de uso" (Marx, 2012[1867], p. 365) 
Por outro lado, dadas a duração da jornada e a intensidade do trabalho, produz-se sempre a mesma massa de valor, independentemente de oscilações no nível geral de produtividade. Contudo, se a produtividade aumenta, a parcela correspondente ao mais-valor cresce na medida em que diminui a parcela correspondente ao valor da força de trabalho, que tende a cair em decorrência da produtividade mais elevada. Ou seja, por cair o tempo de trabalho necessário, aumenta o tempo de trabalho excedente. Evidentemente, interessa ao capital estender o quanto possível o tempo de trabalho excedente. Por isso, a existência de limites (naturais, culturais, legais, etc.) à extensão da jornada de trabalho exige que as "condições técnicas e sociais do processo de trabalho" sejam continuamente transformadas a fim de expandir o tempo de trabalho excedente por meio da redução do tempo de trabalho necessário; em outros termos, visando expandir o mais-valor relativo. Neste contexto, aumenta ou diminui o mais-valor em decorrência da diminuição ou do aumento do valor da força de trabalho, que depende de variação no nível de produtividade nos ramos decisivos cujos produtos compõem os meios de subsistência normais.

Em termos da produção de valor, os ganhos de produtividade podem ter dois efeitos distintos. Se a elevação da produtividade ocorre apenas para um capital isolado (ou alguns poucos) de tal forma que o tempo de trabalho socialmente necessário à produção daquela mercadoria não seja afetado, cresce a massa de valor produzida, uma vez que cada unidade produzida (em maior número, em razão do maior nível de produtividade) continua sendo a encarnação de um valor de mesma magnitude. ${ }^{13}$ Se por outro lado a elevação do nível de produtividade é generalizada, produz-se, como mencionado, a mesma massa de valor a cada jornada de trabalho. Esse valor, todavia, agora se distribui por uma quantidade maior de mercadorias. Cai, portanto, como resultado da redução do tempo de trabalho socialmente necessário, o valor de cada unidade produzida.

O resultado em termos da produção de valores de uso de uso é, ao contrário, inequívoco. Tanto a expansão da jornada de trabalho quanto a elevação dos níveis de produtividade - seja ela pontual, seja ela generalizada - têm como consequência direta a expansão da produção de valores de uso. 
E é essa massa necessariamente crescente de valores de uso que oferece um primeiro indício importante dos desdobramentos materiais da expansão do capital enquanto valor. Em outros termos, indica uma possível debilidade fundamental da noção de desmaterialização.

Até este ponto, esteve pressuposto como constante o número de trabalhadores empregados na produção. Observou-se, a partir da relação entre trabalho excedente e trabalho necessário (a taxa de mais-valor), como os esforços pela expansão do mais-valor desdobram-se no aumento da produção e do produto excedente. Considerando, no entanto, a taxa de mais-valor constante, a massa de mais-valor produzida depende do número de trabalhadores empregados (e varia na razão direta desse número). Tal número é determinado, dentre outros fatores, pela capacidade dos meios de produção de ocupar trabalhadores. Essa capacidade, por seu turno, depende tanto das características técnicas dos meios de produção quanto da magnitude de seu conjunto. Depende, em síntese, da composição técnica do capital, a proporção entre a massa dos meios de produção empregados e a quantidade de trabalho exigida para (e possibilitada por) o seu emprego.

A simples expansão da massa de mais-valor, contudo, não cumpre o objetivo de todo o processo. Como afirmado, as mercadorias devem ter seu valor realizado por meio da venda. Todavia, não apenas isso. $O$ valor realizado na venda deve retornar à circulação como capital. E não apenas o valor equivalente ao capital inicialmente adiantado, mas também parte do mais-valor deve ser aplicada como capital, i.e., deve retornar ao mercado comprando meios de produção e força de trabalho. $O$ capital somente se expande sendo continuamente lançado à circulação em escala ampliada. ${ }^{14}$

A velocidade e a magnitude dessa reprodução em escala ampliada, por depender da produção e da realização de mais-valor, são também determinadas pelos mesmos fatores já analisados que concorrem para a produção desse. Além disso, à medida que o mais-valor é agregado ao capital antigo, aumenta o poder de acumulação do capital, por produzir este massa crescente de mais-valor e, em decorrência disso, por possibilitar que uma parcela cada vez maior do mais-valor seja capitalizada, sem que o fundo de consumo do capitalista precise sofrer redução em termos absolutos, podendo até mesmo aumentar em termos absolutos enquanto declina em

14 "A retirada do dinheiro da circulação impediria totalmente sua expansão como capital, e a acumulação de mercadorias com fins de entesouramento não passaria de uma loucura". (Marx, 2012[1867], p. 687) 
termos relativos. Assim, portanto, quanto maior a magnitude do capital, maior sua capacidade de acumulação. ${ }^{15}$

A acumulação do capital pode ocorrer de duas formas. Como expansão meramente quantitativa do capital empregado, sem mudança em sua composição técnica, ou como expansão acompanhada de transformações qualitativas, como o aumento da produtividade, expresso na elevação da composição técnica do capital. ${ }^{16}$ No curso do desenvolvimento do modo capitalista de produção, os intervalos em que a acumulação ocorre apenas da primeira forma ficam cada vez mais curtos e, à medida que a acumulação com transformação técnica se torna mais frequente - e com ela a elevação da composição técnica -, diminui a capacidade dos meios de produção de ocupar trabalho.

Os novos ramos produtivos (de produtividade mais elevada) têm, portanto, menos poder de empregar força de trabalho. Mas, mesmo nos ramos já existentes, chega o momento de substituição do aparato produtivo, que, assumindo novo nível de produtividade, tende a desempregar trabalhadores antes empregados. No primeiro caso, emprega menos trabalhadores; no segundo, desemprega trabalhadores. ${ }^{17}$ É preciso frisar, entretanto, que a renovação da estrutura produtiva, com o consequente aumento da composição do capital, em geral ocorre em meio à expansão extensiva do escopo da produção capitalista. Isso significa dizer que a repulsão de força de trabalho provocada pelo aumento da produtividade é compensada pela atração de força de trabalho, pela extensão da lógica capitalista a novos mercados, a domínios mais amplos da vida social, a novas regiões, etc.

De qualquer forma, o resultado pode ser enunciado da seguinte forma: no curso da acumulação, os esforços empreendidos pelos capitalistas individuais para a produção, expansão e apropriação do mais-valor tendem a reduzir relativamente a participação do trabalho vivo, a substância do va-

15 A concorrência encarrega-se de impor a cada capitalista a necessidade de expandir seu capital por meio da capitalização de parte do mais-valor, seja em ramos já existentes - exigindo a expansão de seus respectivos mercados -, seja em ramos emergentes ou nascentes, criando mercados inteiramente novos.

16 O "grau de produtividade do trabalho, numa determinada sociedade, se expressa pelo volume relativo dos meios de produção que um trabalhador, num tempo dado, transforma em produto, com o mesmo dispêndio de força de trabalho. A massa dos meios de produção que ele transforma aumenta com a produtividade de seu trabalho". (Marx, 2012[1867], p. 725)

17 "O capital adicional formado no curso da acumulação atrai, relativamente à sua grandeza, cada vez menos trabalhadores. E o velho capital periodicamente reproduzido com nova composição repele, cada vez mais, trabalhadores que antes empregava". (Marx, 2012[1867], p. 731) 
lor, no processo produtivo. Deve o capital, portanto, acelerar seu ritmo de expansão apenas para continuar "ocupando os trabalhadores que se encontram empregados". ${ }^{18}$

Esse ritmo frenético de acumulação gera uma "massa de riqueza social que se torna transbordante", riqueza essa que pode se converter em capital e continuar a alimentar e a reproduzir a expansão do capital, da produção e, também argumentaremos abaixo, do consumo de recursos que necessariamente a acompanha.

\subsection{Coda}

O argumento desenvolvido ao longo desta seção já é capaz de demonstrar, em um nível de abstração ainda bastante elevado, que o impulso à expansão da produção é um elemento inerente à formação socioeconômica regida pelo capital; está inscrito em seu "código genético". Se por um lado, em outras formações sociais pregressas, o aumento da produção apresentava-se como ocorrência acidental ou mesmo como tendência verificada post festum - e, portanto, não como necessidade - no capitalismo, por outro, o imperativo ao crescimento encontra-se fundado no valor enquanto elemento estruturante da produção e da distribuição da riqueza.

Se o processo de produção social é regido pelo valor, i.e., se é produção capitalista, sua expansão constitui-se como necessidade imanente, como absoluto imperativo para a contínua reprodução dos traços fundamentais (p. ex., as relações de trabalho e de propriedade) que caracterizam essa sociedade. Em outros termos, a sociedade capitalista só garante sua contínua reprodução como sociedade capitalista nas bases de uma contínua expansão da produção.

Ainda não é possível, com a análise aqui realizada, afirmar que tal crescimento é necessariamente acompanhado por maior consumo de recursos e emissão de resíduos. Resta, pois, demonstrar em maior detalhe que a produção crescente de valores de uso impõe exigências também crescentes sobre os recursos disponíveis (aqui nos referimos especificamente aos recursos naturais usados como insumos ou como sorvedouros de poluentes). Embora esta seção já ofereça elementos importantes nesse sentido - e a número de trabalhadores que emprega sob seu capital. Esse tema será tratado na próxima seção. 
própria realidade concreta proporciona evidências contundentes de que é isso que de fato ocorre - é preciso aprofundar-se nessa relação entre produção e consumo material.

$\mathrm{Na}$ literatura, há uma clara divisão quando se trata de estabelecer uma conexão entre o crescimento econômico e as exigências materiais impostas ao planeta (seja na forma de matérias-primas, resíduos, seja na forma de emissões, etc.). Parte dos autores proclama que os avanços tecnológicos obtidos até hoje já realizaram a façanha de compatibilizar a expansão da produção a exigências materiais declinantes. Outro grupo aponta o crescimento econômico como a causa fundamental da não realização do potencial poupador da tecnologia, receitando como cura para esse mal avanços tecnológicos em maior velocidade. ${ }^{19}$ Dito de outra forma, a noção de desmaterialização se sustenta, em virtualmente todo o espectro do debate ambiental, com base na ciência econômica, no entendimento de que o progresso tecnológico gera economia de recursos.

A próxima seção busca articular a perspectiva marxiana da dinâmica do desenvolvimento tecnológico (ou, de maneira mais geral, do avanço das forças produtivas) a essa discussão. Neste sentido, as questões mais gerais a serem respondidas são: é possível que avanços tecnológicos "desmaterializem" o crescimento econômico? Ou seja, é possível, no capitalismo, expandir a produção e, ao mesmo tempo, reduzir em termos absolutos as exigências materiais e energéticas da produção?

\section{Desenvolvimento das forças produtivas e os impul- sos aos ganhos de produtividade e eficiência}

A naturalização do imperativo absoluto de expansão do capital oferece uma primeira explicação por que as respostas oferecidas à questão das emissões antropogênicas de GEE (e mesmo a outros problemas ambientais de menor magnitude) passam ao largo de - ou, quando muito, apenas tangenciam - qualquer discussão sobre formas de organização e controle consciente da produção social que tenham potenciais impactos

19 Alguns poucos autores chegam a sustentar a necessidade de operar um decrescimento (conscientemente coordenado) da produção (cf. nota 2). Essa posição - defendida no interior dos parâmetros reprodutivos da sociedade capitalista - é, por tudo que vimos no presente artigo, uma insensatez. 
estruturais capazes de colocar em risco as condições fundamentais de valorização do capital.

Por um lado, o crescimento da riqueza sob a forma de valor é tomado prontamente como a forma universal de crescimento da riqueza. É apenas nesse sentido que o ímpeto expansionista do capital é reconhecido (de forma acrítica). Por outro lado, a contrapartida de tal expansão em termos materiais é em geral abstraída.

Em trabalhos anteriores, tivemos a oportunidade de ilustrar o quão relevante é o papel atribuído a novas tecnologias na elevação dos níveis gerais de eficiência (em geral) e à alegada redução das exigências energéticas da atividade humana por elas possibilitada (em particular) (Sá Barreto, 2014a). Mesmo que as trajetórias de consumo de energia e eletricidade sejam flagrantemente ascendentes - o que, ao menos a princípio, desautorizaria qualquer fantasia a respeito da assim chamada "desmaterialização da produção" -, a justificativa quase unânime é que o desenvolvimento tecnológico até aqui realizado permitiu que aumentos ainda mais acelerados fossem evitados.

$\mathrm{O}$ argumento mais geral consiste em afirmar que novas tecnologias, ao tornarem o processo produtivo mais eficiente, permitiriam continuar expandindo os níveis de produção sem a necessidade de uma expansão proporcional no consumo de insumos, incluídos aí recursos naturais e energéticos.

Colocado nesses termos, contudo, o avanço tecnológico nem sequer engloba integralmente o que normalmente se entende como desenvolvimento tecnológico, deixando de lado transformações técnicas que, por sua natureza, aumentam a demanda por insumos produtivos. A virada do século XIX para o século XX, com o nascimento da indústria do petróleo e da indústria elétrica, oferece alguns exemplos importantes (relacionados ao consumo de energia) desse aspecto em geral negligenciado da tecnologia (Freeman; Soete, 2008). O mundo contemporâneo ainda oferece amplo conjunto de exemplos nesse sentido (inclusive, novamente, no próprio setor petrolífero).

Além disso, mesmo que incorpore a ideia de mudanças como as mencionadas acima, o mero desenvolvimento tecnológico não é nem mesmo equiparável à noção marxiana de avanço das forças produtivas. Os ganhos de eficiência são apenas um aspecto da dinâmica mais abrangente de transformações das forças produtivas, que, em linhas muito gerais, ocorre por duas vias: por mudanças nos meios de produção (tanto dos instrumentos 
de trabalho quanto de matérias-primas e materiais-auxiliares) e por mudanças na organização da produção. A primeira está geralmente associada a avanços tecnológicos. A segunda, não necessariamente. Neste sentido, portanto, também aumentam as forças produtivas por transformações que, embora relacionadas às mudanças técnicas (ou mesmo tornadas possíveis por elas), excedem a dimensão estritamente tecnológica.

A necessidade desse longo preâmbulo justifica-se pela ênfase quase absoluta - presente não somente na literatura econômica, mas também nas publicações do IPCC - dada ao desenvolvimento tecnológico e, particularmente, às tecnologias que trazem consigo a possibilidade de economia de recursos.

No decorrer da presente seção, analisamos como a tendência aos ganhos de eficiência ${ }^{20}$ articula-se a outras dimensões características do processo mais amplo de avanço das forças produtivas e, especialmente, como se insere na dinâmica imanente da produção capitalista, i.e., da produção regida pelo valor e orientada para a máxima expansão possível do mais-valor e, como consequência, do capital.

\subsection{Produtividade e intensidade do trabalho e suas relações com a eficiência}

A produção de mais-valor exclusivamente pela expansão da jornada é típica - embora não tenha deixado de existir, sendo ainda relevante em determinados ramos e localidades - do período em que as condições técnicas de produção se encontravam apenas apropriadas pelo capital, i.e., sem transformações significativas no processo de trabalho. Neste caso, o controle do capital sobre o processo de trabalho no sentido de elevar a eficiência tanto quanto possível transcorre basicamente como controle de desperdícios e utilização adequada dos meios de produção.

No desenvolvimento histórico do sistema, essa base técnica característica da manufatura tornou-se um entrave às necessidades de produção geradas pela própria emergência do modo de produção capitalista. Os limites

20 Muitas vezes produtividade e eficiência são utilizados como sinônimos. Por isso, é importante frisar que, nesta seção do trabalho, nos apropriamos dos termos de maneira distinta. Produtividade sempre vai referir-se à produtividade do trabalho ou à produtividade geral na produção (com as devidas indicações, sempre que necessário). Eficiência, por sua vez, vai sempre se referir à razão entre insumos materiais e produto. Esperamos que a importância ontológica de tal distinção fique clara ao longo da exposição. 
naturais e legais da extensão da jornada de trabalho impõem a necessidade de reduzir o tempo de trabalho da jornada dedicado ao trabalho necessário para estender o tempo de trabalho excedente.

A produção de mais-valor pelo encurtamento do tempo de trabalho necessário exige, para além de certo limite, que a produção capitalista supere o estágio em que as condições de produção se encontravam meramente apropriadas pela relação capitalista de trabalho; que supere, portanto, o estágio de subordinação formal. Exige, assim, que "as condições técnicas e sociais do processo de trabalho" sejam transformadas "a fim de aumentar a força produtiva do trabalho".

O desenvolvimento e a disseminação de máquinas, sistemas de máquinas e, posteriormente, da produção automatizada são, como a exploração da maior produtividade oriunda da cooperação já havia sido, uma resposta do capital às barreiras impostas à extensão da jornada de trabalho. Fazendo o trabalhador trabalhar mais rapidamente, o sistema automatizado (além de elevar o nível de produtividade) concentra mais trabalho a cada período, aumentando sua intensidade, e compensa assim a limitação em termos de duração. Muda, com isso, a proporção em que a jornada se divide em trabalho necessário e trabalho excedente sem que seja necessário aumentar sua duração.

Há algumas diferenças e semelhanças importantes entre os efeitos de um ganho de produtividade e de um aumento da intensidade do trabalho que devem ser sublinhadas. Como observado na seção anterior, a elevação do nível de produtividade tem como efeito o aumento da quantidade produzida de valores de uso num mesmo período de tempo, mas sem variação da massa de valor. Caso tal elevação ocorra nos ramos que tipicamente produzem os meios de subsistência dos trabalhadores, ${ }^{21}$ o tempo de trabalho necessário é reduzido, e, como consequência, o tempo de trabalho excedente é estendido. Em outros termos, cai a parcela do valor novo criado correspondente ao valor da força de trabalho para que possa aumentar a parcela correspondente ao mais-valor.

O aumento da intensidade, por sua vez, condensa mais trabalho em menos tempo e equivale, por isso, a uma jornada mais longa. Por esse motivo, juntamente com a expansão resultante da produção de valores de uso, cresce também a massa de valor produzida a cada período. Dessa for21 Há outros fatores que concorrem para a redução do valor da força de trabalho, que, neste trabalho, ainda não levamos em conta. 
ma, o tempo de trabalho excedente pode aumentar mesmo na ausência de redução no tempo de trabalho necessário. Dependendo das condições de produção que se apresentem (p. ex., eventos naturais que venham a causar impactos negativos, por um dado período, na produtividade), as duas parcelas do valor novo podem até mesmo crescer simultaneamente se a intensidade do trabalho for elevada suficientemente. Como nesse caso a divisão entre valor da força de trabalho e mais-valor independe da contração do tempo de trabalho necessário, ao contrário do que ocorre no ganho de produtividade, o mais-valor produzido pode aumentar independentemente das características do produto (se compõe o conjunto dos meios de subsistência ou não) dos ramos afetados. Uma queda geral de produtividade pode ser, por exemplo, compensada por um aumento da intensidade, caso em que seria reduzido relativamente o mais-valor criado sem que sua magnitude em termos absolutos fosse necessariamente alterada.

Em síntese, o ganho de produtividade traduz-se como expansão do produto para um dado dispêndio de trabalho e período de tempo. Logo, o mesmo valor distribui-se por um volume maior de valores de uso. Com aumento da intensidade, aumenta o produto, porém com maior dispêndio de trabalho para um dado período de tempo. Maior volume de valores de uso e maior massa de valor, portanto. O tempo de trabalho agora se mede não somente segundo sua duração (extensão), mas também segundo sua intensidade (condensação). Equivale dizer que o próprio tempo é condensado, já que um trabalho de intensidade acima da média cria em 6 horas, por exemplo, o mesmo valor (e não somente o mesmo número de valores de uso) que um trabalho de intensidade normal cria em 8 horas.

Deste modo, considerada constante a duração da jornada, tanto a elevação da produtividade quanto a da intensidade do trabalho são formas - que, pela própria natureza de aprofundamento da automatização da produção no processo de avanço das forças produtivas, podem ser (e normalmente são) simultâneas - de aumentar a taxa de mais-valor.

A primeira, pela expansão do mais-valor relativo, que decorre, como apontado, da contração do tempo de trabalho necessário com o aumento da produtividade nos ramos decisivos que compõem os meios de subsistência normais dos trabalhadores. Hoje, não é exagero afirmar que uma parcela relevante desses meios possui alguma relação, mesmo que nem sempre direta, com recursos energéticos. Basta imaginar as necessidades 
de transporte e toda a variedade de bens e serviços básicos que dependem do consumo de eletricidade. Neste sentido, o aumento da eficiência energética concorre, ao reduzir o peso da demanda por energia na fruição e no consumo desses bens e serviços, para o barateamento da força de trabalho e a consequente expansão do mais-valor.

A segunda, pela condensação de mais trabalho em um período fixado de tempo. Em outros termos, pela expansão do mais-valor absoluto. A intensificação do trabalho exige também que se aperfeiçoem os métodos e os meios de produção empregados. A eficiência (em geral) e a eficiência energética (em particular), neste caso, desempenham o papel de tornar possível a aceleração e a complexificação do processo de trabalho. Marx (2012[1867], p. 470; ênfase adicionada), referindo-se à utilização de maquinário pelo capital para contrarrestar as limitações impostas à jornada de trabalho, cita um claro exemplo em que se relacionam, direta e reflexivamente, a elevação da eficiência e o aumento da intensidade do trabalho:

transforma-se a máquina nas mãos do capital em instrumento objetiva e sistematicamente empregado para extrair mais trabalho no mesmo espaço de tempo. É o que se obtém de duas maneiras: aumentando a velocidade da máquina $e$ ampliando a maquinaria a ser vigiada por cada trabalhador, ou seja, seu campo de trabalho. É necessário aperfeiçoar a construção das máquinas para exercer maior pressão sobre o trabalhador. Aliás, esse aperfeiçoamento corre paralelo com a intensificação do trabalho, pois a redução da jornada força o capitalista a administrar da maneira mais severa os custos de produção. O aperfeiçoamento da máquina a vapor aumenta a velocidade do êmbolo e possibilita, com maior economia de força, impulsionar um mecanismo mais volumoso como mesmo motor, não se alterando ou mesmo diminuindo o consumo de carvão. $O$ aperfeiçoamento do mecanismo de transmissão diminui o atrito e, o que tanto distingue a maquinaria moderna da antiga, reduz o diâmetro e o peso dos eixos de transmissão a um minimo em constante decréscimo.

Dessa forma, os aumentos da produtividade e da eficiência não têm como objetivo primário atingir a economia dos fatores - ou seja, poupar recursos em níveis absolutos - mas expandir a massa de valor passível de ser anexada (apropriada) pelo capital. O desperdício de meios de produção (como, por exemplo, matérias-primas e materiais acessórios, dentre os quais é possível se incluir combustíveis em geral e eletricidade) consiste em trabalho objetivado superfluamente despendido. ${ }^{22}$

22 Neste sentido, Marx (2012[1867], p. 229) afirma: "não deve ocorrer nenhum consumo impróprio de matéria-prima e de instrumentais, pois material ou instrumental desperdiçados significam quantidades superfluamente despendidas de trabalho materializado, não sendo, portanto, consideradas nem incluídas na produção do valor". 
Em outras palavras, trabalho que não colabora na composição do valor das mercadorias produzidas. ${ }^{23}$

\subsection{Produtividade, eficiência e os diferenciais apropriáveis de valor}

O valor de cada mercadoria individual é determinado, como vimos, pelo tempo de trabalho médio necessário à sua produção. Significa dizer que o "valor social" 24 de cada mercadoria não é o tempo de trabalho empregado em cada processo produtivo particular; é determinado pelas condições médias de produção no ramo específico de cada mercadoria. Sendo assim, o capitalista detentor da mercadoria, ao levá-la ao mercado, recebe por ela o equivalente ao tempo de trabalho social médio nela contido, ${ }^{25}$ não ao tempo de trabalho diretamente despendido em sua produção. É possível concluir então que, se o tempo de trabalho diretamente despendido for inferior ao tempo médio necessário, esse capitalista estará apropriando-se de quantidade de trabalho que de fato não empregou; de quantidade de valor superior a que se apropriaria caso o tempo empregado por ele fosse o tempo médio social. Analogamente, se o tempo de trabalho empregado fosse superior ao tempo médio, estaria se apropriando de uma quantidade de trabalho inferior à de fato empregada.

Suponhamos, por último, que o tempo empregado é exatamente o tempo médio. Se esse capitalista individual realiza a introdução de alguma modificação técnica que aumenta a produtividade do trabalho, a quantidade necessária de trabalho para que produza qualquer volume dado de mercadorias diminuirá. Como tal diminuição ocorre apenas para um processo produtivo isolado, o "valor social" da mercadoria não sofre alterações, embora o "valor individual" de cada um de seus exemplares produzidos com o novo método seja reduzido. O capitalista poderá apropriar-se, então, de uma massa de

23 "É da maior importância que durante o processo [...] só se empregue o tempo de trabalho socialmente necessário. [...] Só se considera criador de valor o tempo de trabalho socialmente necessário". (Marx, 2012[1867], p. 223)

24 O valor, como demonstrado, é sempre social. Aqui, no entanto, utilizamos os qualificativos "social" e "individual" (sempre entre aspas) para tornar evidente de maneira mais sintética as diferentes magnitudes de trabalho diretamente aplicadas na produção da mercadoria. Sendo assim, "valor social" corresponde ao valor (e, por isso, ao tempo de trabalho socialmente necessário) e "valor individual" corresponde ao tempo de trabalho diretamente aplicado.

25 Estamos aqui fazendo a suposição simplificadora que as mercadorias se vendem por seus valores. 
valor que não corresponde diretamente ao trabalho contido em sua mercadoria: o mais-valor extra. Em outros termos, o diferencial de produtividade facultou ao capitalista apropriar-se de tempo de trabalho dos concorrentes. A possibilidade de apropriação dessa diferença entre o valor recebido na venda e o "valor individual" da mercadoria gera um impulso para a implementação de novas técnicas, tecnologias ou formas de organização do processo produtivo capazes de ampliar a produtividade do trabalho.

Ocorre, como sublinhado na seção anterior, que tal elevação da produtividade resulta necessariamente em maior volume de mercadorias. Para que o capitalista se aproprie do mais-valor extra, é imperativo que a venda dessas mercadorias seja bem-sucedida. Se não houver a venda, o valor nelas contido não será realizado e de nada terá valido o ganho de produtividade. O capitalista deve agora encontrar um mercado para suas mercadorias tanto mais extenso quanto maior tiver sido a expansão material de sua produção. ${ }^{26}$

Todavia, esse mecanismo de apropriação do mais-valor extra funciona apenas para os primeiros capitalistas individuais pioneiros na nova forma de produzir. $O$ próprio mais-valor extra desaparece à medida que o novo nível de produtividade é generalizado ${ }^{27}$ e o "valor social" da mercadoria tende a aproximar-se de seu "valor individual". ${ }^{28}$

Foi salientado anteriormente que a determinação do valor exige que não mais que o tempo de trabalho social médio seja aplicado na produção da mercadoria. Caso contrário, haverá trabalho superfluamente despendido, o trabalho realizado no tempo que ultrapassa o tempo socialmente necessário. ${ }^{29}$ Tal lei é válida, contudo, não somente para o trabalho vivo, mas também para o trabalho passado, objetivado. A partir disso, afirmamos que a determinação do valor também pressupõe que os meios de produção tenham

26 A apropriação do mais-valor extra depende apenas da realização do valor cristalizado nessa massa aumentada de mercadorias. Para uma análise dos obstáculos à tal realização, cf. Sá Barreto (2014b).

27 Para os capitais que, porventura, se encontrem ainda abaixo no novo nível geral de produtividade, existe a alternativa (em geral empregada) de aumentar a intensidade do trabalho para compensar essa desvantagem.

28 De acordo com Marx (2012[1867], p. 369), "esse mais-valor extra se desvanece quando se generaliza o novo modo de produção, desaparecendo, assim, a diferença entre o valor individual das mercadorias que eram produzidas mais barato e seu valor social".

29 O trabalho superfluamente despendido também pode ser caracterizado como o trabalho objetivado que, mesmo atendendo às condições médias, não é absorvido pelas necessidades sociais, manifestadas no mercado, i.e., aquele trabalho incorporado em mercadorias não vendidas; valor não realizado. 
sido aplicados na quantidade e na qualidade normais reinantes em dado período e que, como consequência, um primeiro impulso à elevação dos níveis de eficiência se manifesta como controle de desperdícios. A discussão anterior sobre o mais-valor extra permite que se façam observações adicionais.

A análise do mais-valor extra centrada na produtividade refere-se especificamente à contínua tentativa do capital de baratear as mercadorias por meio da diminuição da participação relativa do trabalho vivo em sua produção. Em outros termos, pela redução do valor novo, que corresponde à soma do capital variável e do mais-valor.

Há ainda, entretanto, a parcela correspondente ao valor do capital constante transferido à mercadoria. Quando cresce a produtividade, transformam-se mais meios e objetos de trabalho em produto em um dado período. Aumenta, portanto, o consumo material de matérias-primas e materiais acessórios, dentre eles toda a variedade de recursos energéticos necessários à produção. ${ }^{30}$ À medida que se expande a massa dos meios de produção, o trabalho vivo conserva e transfere uma massa crescente de valor. Tende a aumentar, relativamente ao valor novo, o valor transferido do capital constante à mercadoria.

Como qualquer outra mercadoria, os meios de produção têm seu valor determinado pelo tempo de trabalho socialmente necessário à sua produção. $O$ valor transferido às mercadorias no processo produtivo pode sofrer variação caso haja mudanças nesse tempo. Um maquinário já em operação, por exemplo, vai transferir menos valor se o tempo médio necessário à sua produção sofrer redução. Neste sentido, Marx (2012[1867], p. 245) sublinha:

Se muda o tempo de trabalho socialmente exigido para sua produção, [...] verifica-se uma reação sobre a mercadoria antiga, que não passa de exemplar isolado de sua espécie, cujo valor sempre se mede pelo trabalho socialmente necessário, isto é, pelo trabalho necessário nas condições sociais presentes. [...] Se, em virtude de uma invenção, se reproduz uma máquina da mesma espécie com menos dispêndio de trabalho, sofre a máquina antiga uma desvalorização e passa a transferir ao produto proporcionalmente menos valor.

O raciocínio de Marx pode ser estendido para os meios de produção que consistem em matérias-primas e cujo valor é em geral transferido integralmente à mercadoria a cada processo produtivo (enquanto o valor dos meios de trabalho é transferido ao produto ao longo de sua vida útil). Su-

30 "A quantidade de matéria-prima consumida num tempo dado por determinada quantidade de trabalho aumenta na mesma proporção em que a produtividade cresce". (Marx, 2012[1867], p. 414-5) 
pondo que a mencionada invenção seja um maquinário ou instalações e equipamentos - ou ainda uma nova forma de gerir o processo produtivo - que reduzam as necessidades de consumo de matérias-primas na produção e que, além disso, tal inovação não seja generalizada, surge (como no caso discutido do aumento da produtividade) um diferencial entre o "valor individual" da mercadoria e seu "valor social". Como a parcela correspondente ao capital constante que compõe o valor da mercadoria é também determinada pelas condições sociais médias de produção em um dado ramo, mesmo que esse processo produtivo reconfigurado utilize menos matéria-prima e que, por isso, o "valor individual" do produto seja reduzido, seu "valor social" permanece o mesmo.

Quanto maior for o nível de eficiência em relação ao nível social médio (no sentido de facultar que se consumam menos matérias-primas para cada volume dado de produto), maior será esse diferencial apropriável de valor. ${ }^{31}$ Há, como consequência, um claro incentivo a forçar continuamente a expansão dos limites da fronteira de eficiência, inclusive, evidentemente, a eficiência energética.

Por último, é necessário considerar o valor dos refugos e resíduos do processo produtivo. Mesmo que parte das matérias-primas e material auxiliar seja transformada necessariamente em refugos ou resíduos - ou seja, se a sua geração é resultado do emprego das condições médias de produção -, o valor dessa fração inutilizada é também transferido ao produto final. A esse respeito, citando o exemplo da produção de fios de tecido, Marx (2012[1867], p. 241) afirma:

É mister transformar o valor de uso de 15 quilos de algodão em refugo imprestável, para se produzir 100 quilos de fio. A destruição deste algodão é condição necessária à produção do fio. Isto se aplica a todos os refugos do processo de trabalho, na medida em que eles não constituam novos meios de produção e, em consequência, novos valores de uso.

Dois aspectos importantes devem ser observados. Por um lado, o impulso anteriormente descrito para a elevação do nível de eficiência tende a ter, como consequência natural da diminuição do volume de matérias-primas necessárias a qualquer dado nivel de produção, a redução (também relativa) da quantidade de refugos e resíduos produzidos. Nesse caso, essa redução resulta de um efeito secundário não intencional - ainda que possivelmente desejável - de modificações motivadas pelo objetivo imediato de aumen$31 \bigcirc$ mecanismo de apropriação e o processo de desaparecimento desse diferencial são os mesmos descritos anteriormente. 
tar a eficiência e, com isso, o mais-valor apropriado na forma de lucros.

Por outro lado, parece razoável admitir que boa parte desses refugos e resíduos consista em substâncias e materiais poluentes, ${ }^{32}$ que, dessa forma, seja do interesse da população, por exemplo, tratar, impedir ou limitar a sua produção. Os interesses do capital, entretanto, convergem nesse sentido apenas na medida em que a geração de resíduos é contida da maneira mencionada no parágrafo anterior.

Se uma medida qualquer - empreendida pelo capital com o objetivo de reduzir a geração de refugos e resíduos para além do nível médio - tiver um efeito poupador de capital, será esse efeito (e seus desdobramentos em termos de apropriação de valor) a principal motivação para implementá-la, não a redução dos materiais poluentes em si. Por outro lado, caso a medida seja eficaz na redução dos resíduos, mas não seja ao mesmo tempo poupadora de capital, não há motivo, com base na perspectiva da valorização do capital, para colocá-la em prática.

Sendo assim, para qualquer nível considerado de eficiência e, em consequência, para qualquer nível considerado normal de produção de refugos e resíduos, não há incentivos para o capital em reduzir tal produção além das reduções já proporcionadas por eventuais ganhos de eficiência. O emprego de trabalho (vivo ou objetivado) específica e exclusivamente voltado a esse objetivo teria necessariamente o caráter de trabalho superfluamente despendido.

\section{Considerações finais}

Pela análise realizada até aqui, conclui-se que o processo de avanço das forças produtivas traz consigo ao menos três dimensões distintas, das quais as duas primeiras são geralmente negligenciadas: a elevação dos níveis de produtividade, de intensidade do trabalho e de eficiência. A noção de desmaterialização da produção, por outro lado, supervaloriza apenas uma dimensão restrita da dinâmica de desenvolvimento tecnológico: os ganhos de eficiência, que poupam recursos, porém apenas em termos relativos.

Observou-se anteriormente que as duas primeiras dimensões (produtividade e intensidade) não apenas frustram as expectativas de desmate(ou não podem ser) reaproveitados como valores de uso. 
rialização como, ao contrário, aumentam as exigências de consumo dos meios de trabalho, de matérias-primas e materiais acessórios, dentre os quais se inclui toda a variedade de recursos energéticos que participam da produção.

Mais importante que a constatação dos limites da perspectiva que sustenta a possibilidade da produção imaterial, contudo, é a demonstração de que os processos que impõem tais limites possuem dinâmica própria e uma causa raiz que impulsiona seu movimento. $O$ objetivo consciente de elevar a força produtiva do trabalho é a máxima expansão possível da massa de lucro. ${ }^{33}$ Isso o capital consegue de quatro formas: (i) contraindo o tempo de trabalho necessário pela elevação do nível de produtividade e, consequentemente, estendendo o tempo de trabalho excedente e aumentando o mais-valor relativo; (ii) criando um diferencial entre o "valor individual" e o "valor social" de suas mercadorias pelo aumento da produtividade do trabalho e dos níveis de eficiência do processo produtivo; (iii) comprimindo o trabalho que seria realizado em uma jornada normal em períodos de tempo cada vez mais curtos, por meio da maior intensidade imposta no processo de trabalho; (iv) e, finalmente, pela eliminação imperativa de desperdícios (de trabalho vivo e de trabalho objetivado, incorporado nos meios de produção) no processo produtivo, obtida pela aplicação/utilização ao menos das condições sociais médias de produção e dos níveis médios de produtividade, intensidade e eficiência.

Adicionalmente, constatou-se que, pela própria lei que determina o valor das mercadorias como o tempo de trabalho socialmente necessário à sua produção, a redução de refugos e resíduos da produção, nos quais se incluem as emissões de GEE, pode apenas ser realizada como um resultado secundário dos processos apontados no parágrafo acima. Para além disso, o emprego de capital (sob qualquer forma) para esse fim constituir-se-ia como trabalho superfluamente despendido, em franca oposição às necessidades autoexpansivas do capital.

Vale ainda frisar que a liberdade do capitalista em se sujeitar ou não à série de impulsos demonstrados ao longo do artigo é meramente formal. Sua vontade individual é constrangida pela concorrência entre capitais e, por isso, desempenha um papel secundário. Se ele não age dessa forma, buscando sempre elevar as forças produtivas sob seu comando - seja de

33 Neste trabalho, ainda abstraímos possíveis divergências entre a massa de lucro e a massa de mais-valor. 
maneira pioneira, seja de maneira retardatária -, seu capital corre o risco de ser destruído ou absorvido por outro de maior porte. Se ele não age "de acordo", portanto, fica exposto ao risco de perder, pela ação da concorrência, a condição de capitalista. Os impulsos convertem-se, por conseguinte, em compulsão, em imperativo. Neste sentido, Marx afirma (2012[1867], p. 369) que a "mesma lei que determina o valor pelo tempo de trabalho e que leva o capitalista que aplica o novo método a vender sua mercadoria abaixo do 'valor social' impele seus competidores, coagidos pela concorrência, a adotar o novo modo de produção".

Todo o argumento desenvolvido ao longo das duas seções pode ser sintetizado como um triplo movimento. Primeiramente, ${ }^{34}$ tendem a avançar as forças produtivas da sociedade. Os ganhos de eficiência energética podem figurar como condição ou como consequência desse movimento (ou mesmo como ambos), seja possibilitando transformações econômicas profundas e abruptas no interior da produção capitalista, seja como importante elemento na luta incessante pela redução dos custos de produção. Entretanto, independentemente do papel que desempenham tais ganhos em cada caso específico, a energia (em geral) e a eficiência energética (em particular) são indissociáveis dessa tendência. Em segundo lugar, a generalização dos processos de maior produtividade, ao mesmo tempo em que faz avançar as forças produtivas da sociedade, reduz, exatamente por tal motivo, o tempo de trabalho necessário na produção de mercadorias. Tende a cair, portanto, seu valor. Em terceiro lugar, lembrando que a natureza do capital é autoexpansiva - que, portanto, a massa de valor produzida e apropriada deve aumentar continuamente -, a única alternativa à queda do valor unitário é a expansão da produção em proporção que mais que compense as perdas relativas em valor.

E, assim sendo, podemos resumir os resultados de todo o processo descrito até aqui como: ${ }^{35}$ (i) avanço das forças produtivas, que tem não apenas o aumento da eficiência (inclusive, claro, a eficiência energética), mas também da produtividade e da intensidade do trabalho como elementos-chave; e (ii) a expansão da produção e o consequente aumento da demanda e consumo de recursos (inclusive os energéticos). Para ilustrar com um caso

34 Este ordenamento refere-se apenas à forma de exposição. De maneira alguma, é indicativo de uma ordem lógica ou cronológica.

35 Evidentemente os resultados e efeitos não se resumem a esses dois. Estamos apenas dando o destaque aos efeitos pertinentes à presente discussão. 
concreto relacionado à grande questão ambiental de nosso tempo, lembramos que, embora a intensidade energética mundial tenha apresentado redução contínua nas últimas três décadas (20,5\%, entre 1980 e 2009), o consumo de energia primária cresceu, no mesmo período, $68,5 \% .{ }^{36}$

Conclui-se, por todo o exposto, que as dinâmicas de evolução das forças produtivas da sociedade (incluídos aí, como momentos parciais, o avanço tecnológico e a elevação dos níveis de eficiência) e do consumo material gerado pela atividade produtiva são, consideradas em sua totalidade, na presente formação social, resultados de uma mesma causa - a saber, a predominância da forma mercadoria e, portanto, a produção regida pelo valor.

Sendo assim, existem limites estruturais objetivos ao descolamento das tendências de expansão da produção e do consumo material no interior desta dinâmica; a dinâmica própria da sociedade capitalista. Para que fique mais claro, a elevação dos níveis de eficiência é parte da dinâmica que conduz a produção a expandir suas demandas materiais. A eficiência não pode, neste contexto, ser apresentada como um deus ex machina para solucionar os problemas ambientais dessa demanda ascendente. Em outras palavras, a plena realização de algo que se assemelhe aos anseios expressos no conceito de desmaterialização exige a superação definitiva da presente formação socioeconômica.

\section{Referências}

BURKETT, P. Marxism and ecological economics: Toward a red and green political economy, Bostom: Brill, 2006.

COSTANZA, R. et al. An introduction to ecological economics. Boca Raton: St. Lucie Press, 1997.

FREEMAN, C.; SOETE, L. A economia da inovação industrial. Campinas: Editora Unicamp, 2008.

IPCC. Synthesis report. In: Climate Change 2007: Contribution of Working Groups I, II and III to the Fourth Assessment Report of the Intergovernmental Panel on Climate Change [Pachauri, R.K. and Reisinger, A. (Eds.)], Cambridge: Cambridge University Press, 2007.

KALLIS, G. In defense of degrowth. Ecological Economics, v. 70, n. 5, 2011.

MARX, K. Grundrisse: manuscritos econômicos de 1857-1858. São Paulo: Boitempo, 2011

MARX, K. O Capital: Crítica da economia política, livro I. Rio de Janeiro: Civilização Brasileira, [1867] 2012.

36 Dados disponíveis na página da U.S. Energy Information Administration (https://www.eia.gov/). 
MEDEIROS, J. L.; SÁ BARRETO, E. Lukács e Marx contra o "ecologismo acrítico": Por uma ética ambiental materialista. Economia e Sociedade, v. 22, n. 2, 2013.

MÉSZÁROS, I. Para além do capital: Rumo a uma teoria da transição. São Paulo: Boitempo Editorial, 2002.

PEARCE, R.; TURNER, R. Economics of natural resources and the environment. Baltimore: The John Hopkins University Press, 1990.

SÁ BARRETO, E. Para uma reinterpretação marxiana do nexo entre eficiência energética e consumo de energia. In: ENCONTRO NACIONAL DE ECONOMIA, 38., 2010, Salvador. Anais... Salvador: Anpec, 2010.

SÁ BARRETO, E. Para uma reinterpretação teórica dos desafios socioeconômicos da política climática contemporânea. Sustentabilidade em Debate - Brasília, v. 5, n. 2, p. 162-178, mai/ ago 2014a.

SÁ BARRETO, E. As múltiplas dimensões da exigência imposta à esfera do consumo pela dinâmica do capital: elementos para o debate ambiental. REVISTA Soc. Bras. Economia Política, São Paulo, n 37, p. 143-168, janeiro 2014b.

VAN DEN BERGH, J. C. J. M. Environment versus growth: A criticism of "degrowth" and a plea for "a-growth". Ecological Economics, v. 70, n. 5, 2011.

\section{Sobre o autor}

Eduardo SáBarreto - eduardo.barreto@ufff.edu.br

Universidade Federal de Juiz de Fora, Juiz de Fora, MG.

\section{Sobre 0 artigo}

Recebido em 14 de novembro de 2013. Aprovado em 11 de novembro de 2014. 